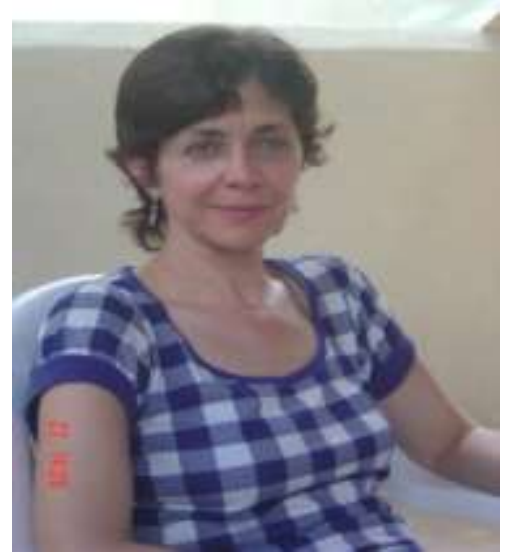

\title{
Alfabetização na inclusão
}

Entrevistadora:Amarílis Hernandes Santos

Formação: Aluna da graduação de Pedagogia -USP

Formada em Ciências Biológicas -Mackenzie

Contato: amarilishernandes@yahoo.com.br

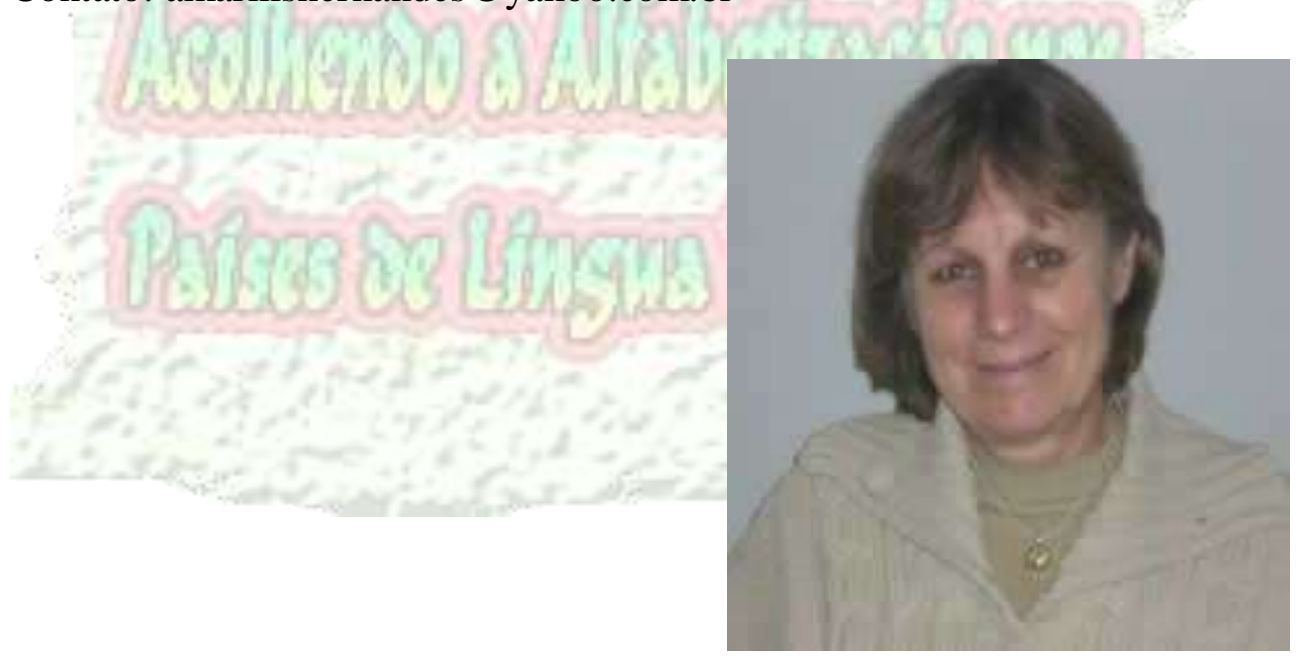

Entrevistada: Angela M. Quadros Cioffi

Formação: Magistério, com Especialização em Educação Pré-Escolar.

Pedagogia, com Habilitação em Administração Escolar; Orientação Escolar; Supervisão Escolar.

Educação Especial: Habilitação em Ensino para Deficientes Mentais e em Ensino para Deficientes Visuais (FEUSP).

Curso de Aperfeiçoamento: Diagnóstico e Inclusão Escolar de Crianças com Distúrbios Globais do Desenvolvimento (Psicologia - USP). Curso Extensivo de formação em Dislexia na Associação Brasileira de Dislexia (ABD). 
Amarílis: Por que você decidiu alfabetizar crianças com deficiência intelectual?

Ângela: No quarto ano do Magistério, já pensava em escolher esta área da Educação, a Especial! O primeiro contato que tive com sala de aula foi numa Escola Especial. Aí tive a certeza que este seria o meu caminho...

Sou professora na SAAI (Sala de Atendimento e Acompanhamento à Inclusão), na Prefeitura de São Paulo, que atende alunos com deficiência intelectual e ou associada a outras deficiências, como a física, visual, o autismo... São alunos matriculados e que frequentam o ensino regular no horário contrário a esse atendimento. Atendo alunos do ensino fundamental II, de $5^{\mathrm{a}}$ a $8^{\mathrm{a}}$. Séries, da mesma Unidade Escolar, EMEF Profa. Maria Alice Borges Ghion. Os grupos são organizados conforme faixa etária, interesse e desenvolvimento escolar. Eles não têm outro atendimento multidisciplinar de saúde (fono, terapia ocupacional, psicologia...) . Não tem ajuda dos pais nas tarefas da escola. A responsabilidade fica por conta da escola e do professor da sala regular... Procuramos na SAAI, acompanhar alunos é professores auxiliando-os no que precisam para um melhor rendimento e fazendo um acompanhamento na sala regular, e sabendo ler e escrever, entender $\mathrm{e}$-interpretar o texto, Isto ajuda muito nas diferentes disciplinas e conteúdos curriculares. Entendo alfabetização como leitura de tudo, de mundo... através de várias linguagens e possibilidades... e não se aprende só na escola!

O aluno escrevendo, lendo, fazendo cálculos básicos, sente-se incluído, participando do processo escolar, com atividades adaptadas para que consiga executar tarefas propostas.

Esta é uma das funções do professor de SAAI, melhorar a auto-estima, segurança e aprendizagem do aluno com deficiência intelectual! 
Amarílis: Quais as maiores dificuldades que você enfrenta para alfabetizar crianças com necessidades especiais?

Ângela: Acredito ser a alfabetização uma das mais importantes tarefas e talvez em alguns casos a mais difícil.

Precisamos respeitar o ritmo e desempenho de cada um. No caso da deficiência intelectual é muito lento e precisa de muitos recursos, material concreto de apoio. Uso material diversificado, jogos, livros, DVDs, histórias, textos dos mais variados... Letras móveis de vários materiais e texturas... Material impresso, enfim tudo o que vejo guardo para que seja utilizado como mais um recurso, em apoio... Sabemos também que a dificuldade de comunicação, linguagem, pobreza de vocabulário, memória, atenção, organização de pensamento, abstração, percepção e sequência lógica, psicomotricidade são características da D.I., e também requisitós tão importantes para a alfabetização.

Acredito na aprendizagem do aluno com deficiência intelectual, desde que tenha variedade e adaptação de materiais, recursos, currículos e técnicas, há a melhora na aprendizagem da leitura e escrita. É um processo muito lento, mas, na maioria das vezes, prazeroso para o aluno e para o professor!

Amarílis:- Oque você acha do construtivismo?

Ângela: A concepção construtivista permite ao aluno expor o que sabe; refletir e pensar sobre o uso da linguagem, participar e tentar resolver problemas do dia a dia; não há erro, precisando mais tempo para a construção do conhecimento que é particular de cada um e compartilhada com outras aprendizagens. Procuro ter uma postura construtivista respeitando o ritmo e aprendizagem de cada um deles, o momento em que estão na aprendizagem da leitura e escrita, como já escrevem e estão lendo, reforçamos a ortografia, entendimento e interpretação de textos para que se 
sintam seguros e capazes de participar das aulas da sala regular.Construímos juntos o processo de aprendizagem.

Amarílis: Qual o método que você utiliza para alfabetizar? Fale um pouco como você o utiliza.

Ângela: É difícil determinar qual método de alfabetização é melhor, para quem o mais eficiente para alunos com D.I. Creio que não há um método específico para alfabetizá-los, pois há prós e contras, sucessos e insucessos, e limitações em todos eles. Atendo um aluno com hiperlexia que aprendeu a ler com menos de dois anos de idade, mas na idade escolar não sabia escrever e não entendia o que lia, não tinha significado algum para ele, além de decodificar letras. Pesquisando, li que eles não suportam escrever, e sua maior dificuldade, e muito grave, é a comunicação, a linguagem oral. Como alfabetizar, escrever, pedir para ler com entendimento e interpretação? Fui descobrindo caminhos com ele, de qual era a melhor forma de linguagem, comunicação, escrita para ele. Foi através de cópias com significados, de objetos e situações de sua vida diária. Hoje ele conversa, responde, tem umá fala com entendimento, escreve, desenha, participa das aulas de Artes, Educação Física e Sala de Leitura, fazendo atividades com-adaptações e apoio individual. Já consegue mais esta leitura de mundo!

Atendo alunos individualmente na mesma turma, pois cada um está num momento de aprendizagem. Preciso priorizar o aluno, o que ele precisa, criar estratégias, atividades e recursos que facilitem sua aprendizagem, melhore sua autoestima e principalmente sua autonomia, sem frustrações e possíveis insucessos. Acredito no método sintético, do simples para o complexo, da parte para o todo: letras, sons, palavras, frases e textos. É sistemático, lógico e organizado, sequencial. Como parte do simples para o complexo, e os alunos com D.I. apresentam dificuldades para elaborar e avaliar a escrita e tem o vocabulário pobre, raciocínio lento e dificuldades 
de memória, precisam de apoio e ajuda constante na aprendizagem, memorização. Precisam mais atenção e cuidado do professor. O método silábico começa com a apresentação das sílabas, uma de cada vez, fichas de leituras com silabário, formação de palavras e exercícios de fixação, memorização de sílabas simples e complexas.

Com as palavras formadas dos silabários escrevemos outras palavras, frases. Creio que no sintético vamos resolvendo as dificuldades conforme aparecem, com atividades de leitura, escrita, textos variados. É preciso termos a preocupação se o aluno entende, compreende o que lê e escreve. O professor deve despertar o interesse do aluno para falar, ler, escrever, ampliar o seu vocabulário. Superar as dificuldades que o aluno apresenta. No método analítico, global, do todo para as partes, ou do texto para as letras é mais difícil para o aluno com D.I. perceber o processo da escrita. Alguns alunos disléxicos e erroneamente diagnosticados como D:I. não conseguem alfabetizar-se com o método global, precisam do método fônicô. Creio que não há uma receita pronta, com o que há a ser feito tão definido. Podemos começar com um método e perceber que não dá certo e, assim, partimos para outro. O importante é o aluno aprender da melhor forma.

Amarílis:Você já fez uso de cartilhas? Se sim, explique como foi sua experiência.

Ângela: Sim, já fiz uso na Escola Especial como livro de apoio. Os alunos gostam de livros, de fazer lições. E hoje, penso que muitos daqueles alunos deveriam e tinham o direito de estar numa escola regular, sabiam ler e escrever, entender dentro de suas limitações. As cartilhas e livros de exercícios de alfabetização têm atividades organizadas, sequenciadas, letra cursiva, e eles precisam desta lógica. Estou tentando com uma aluna que não consegue memorizar nem as vogais. Vou tentar apela imagem visual dos desenhos nas letras. 
Amarílis: Fale sobre o prêmio que você recebeu da Prefeitura Municipal de São Paulo.

Ângela: Em 07 de outubro de 2009, recebi o título de "Professor Emérito" pelo trabalho desenvolvido na Secretaria da Educação de São Paulo (entregue pelo Sr. Gilberto Kassab, Prefeito, e Sr. Alexandre Schneider, Secretário da Educação, da cidade de São Paulo), por ações que contribuem com a inclusão de alunos com necessidades especiais, como também para com o trabalho de seus pares, professores.

Desde 2002, com o trabalho junto a alunos com necessidades especiais na PMSP, SAAI, meu compromisso com a educação é ainda maior hoje, de respeito às diferenças, de compreensão com o ser humano que contribuem cada vez mais para a inclusão dos alunos com D.I. e de suas famílias.

É assim que penso sobre a Educação Especial!

Pensando assim, estaremos pensando no melhor para todos, não só para a Educação Especial!

Texto recebido em setembro de 2010.

Texto aprovado para publicação em novembro de 2010.

\section{Como citar este texto:}

SANTOS, A. H.. A alfabetização na inclusão. Revista Acolhendo a Alfabetização nos Países de Língua Portuguesa, Brasil, São Paulo, volume 1, $\mathrm{n}^{\mathrm{o}}$. 10, pp. 169 - 174, Mar. 2011. Disponível em: <http://www.acoalfaplp.net>. 